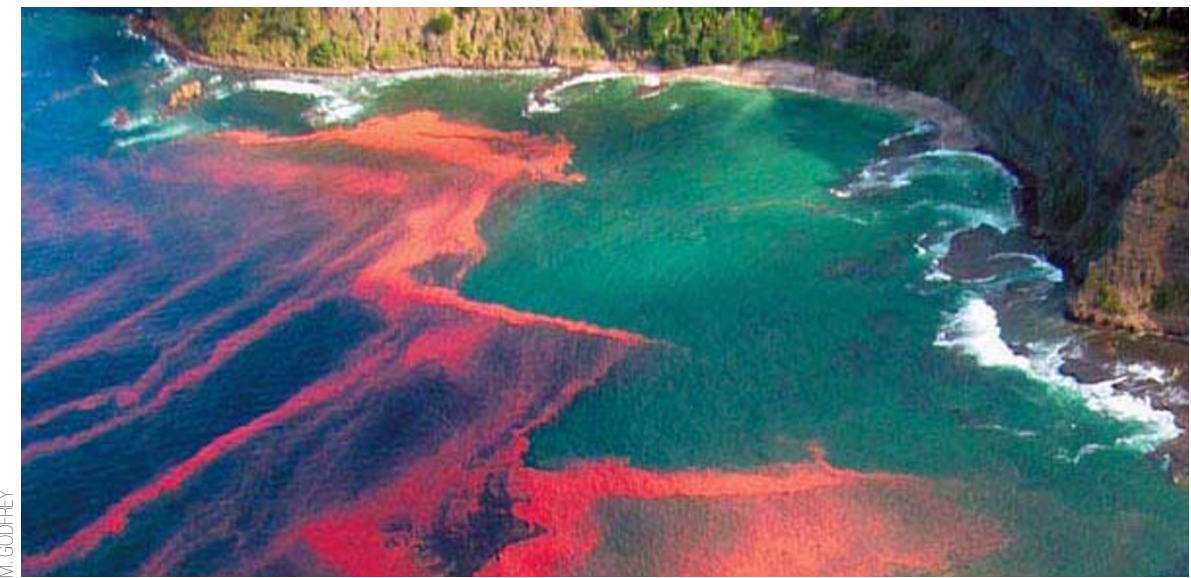

$1 \times 10^{12} \mathrm{gP} \mathrm{yr}^{-1}$; Amer. J. Sci. 282, 401- 450; 1982 ) is probably equivalent to the natural background flux, doubling the total reactive phosphorus load and causing difficulties in coastal waters. The total background flux is probably greater than $11 \times 10^{12} \mathrm{gP} \mathrm{yr}^{-1}$, so the suggested tolerable boundary for the human impact would exceed $110 \times 10^{12} \mathrm{gP}$ $\mathrm{yr}^{-1}$, enough to deplete known phosphorus reserves in less than 200 years and certainly not sustainable.

Unfortunately, policymakers face difficult decisions, and management based on thresholds, although attractive in its simplicity, allows pernicious, slow and diffuse degradation to persist nearly indefinitely. Through the Holocene, atmospheric $\mathrm{CO}_{2}$ was nearly constant; nature mitigated the effects of humans. The human impact on the carbon cycle now exceeds the natural buffering capacity of the Earth system, leading to cumulative changes in the environment for life in every corner of the planet. When these changes are more rapid than evolution, extinctions mount and the ability of the planet to support life is diminished (Nature 427, 145-148; 2004). Setting boundaries is fine, but waiting to act until we approach these limits merely allows us to continue with our bad habits until it's too late to change them.

Published online: 23 September 2009

doi:10.1038/climate.2009.93

William H. Schlesinger is President of the Cary Institute of Ecosystem Studies in Millbrook, New York.

e-mail: schlesingerw@caryinstitute.org

\title{
Keep off the grass
}

\section{STEVE BASS}

\section{Humanity must learn to live within a stable Holocene environment, but the boundary limit for land use depends on more than the amount of surface covered.}

$\mathrm{J}$ ohan Rockström and colleagues' description of planetary boundaries (Nature 461, 472-475; 2009) is a sound idea. We need to know how to live within the unusually stable conditions of our present Holocene period and not do anything that causes irreversible environmental change.

Planetary boundaries build on a long and respectable tradition of research and thinking on ecological limits, such as the 'limits to growth' thesis of 1972, as well as more recent developments, such as the idea of the ecological footprint and the Millennium Ecosystem Assessment - though Rockström and colleagues would have done well to acknowledge these foundations.

Their paper has profound implications for future governance systems, offering some of the 'wiring' needed to link governance of national and global economies with governance of the environment and natural resources. The planetary boundaries concept should enable policymakers to understand

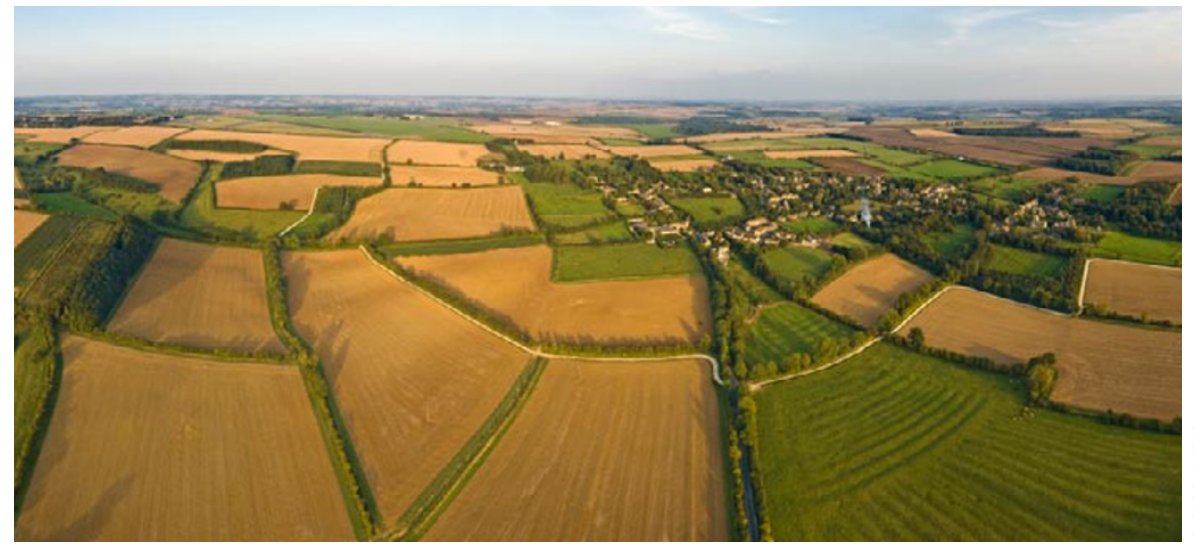

more clearly that, like human rights and representative government, environmental change knows no borders.

That said, there is much work to be done before the concept can be used practically - before it can be 'operationalized'. What policymakers need is a clear instruction that says something to the effect of 'keep off the grass'. What the planetary boundaries paper provides is closer to an index of lawn carrying capacity expressed in terms of soil engineering and grass regeneration.

One of the boundaries described is landuse change. The authors say there needs to be a limit on the amount of the world's land surface that is converted for farming or industry. They suggest that no more 
than 15 per cent of land should be used as cropland. Current crop cover is around 12 per cent.

Rockström and colleagues will be the first to accept that the 15-per-cent figure is not a consensus value that can be validated in the research literature, but rather is based on a sensible - though apparently arbitrary - expansion factor. In that regard, they need to be prepared for at least two critical questions. First, if a figure of 15 per cent cannot be authenticated scientifically, policymakers will want to know why they should pay attention to it. Why shouldn't, say, 20 per cent of land surface be used for farming? Or indeed, why not 10 per cent?

Second, readers will want to know the basis for the authors' contention that land- use change undermines human well-being. If anything, the opposite has probably been more true: converting land for farming and for industry has clearly delivered a great deal of well-being, and populations will continue to find such land-use change both attractive and desirable.

What research does tell us is that the sustainability of land use depends less on percentages and more on other factors. For example, the environmental impact of 15 per cent coverage by intensively farmed cropland in large blocks will be significantly different from that of 15 per cent of land farmed in more sustainable ways, integrated into the landscape.

The boundary of 15 per cent land-use change is, in practice, a premature policy guideline that dilutes the authors' overall scientific proposition. Instead, the authors might want to consider a limit on soil degradation or soil loss. This would be a more valid and useful indicator of the state of terrestrial health. More satisfactory policy guidelines on land use could subsequently be constructed, based on this and other relevant planetary boundaries.

Published online: 23 September 2009

doi:10.1038/climate.2009.94

Steve Bass is a Senior Fellow at the International Institute for Environment and Development in London and a former Chief Environment and Infrastructure Advisor to the UK Department for International Development. e-mail:steve.bass@iied.org

\title{
Tangible targets are critical
}

\author{
MYLES ALLEN
}

\section{Setting a limit on long-term atmospheric carbon dioxide concentrations merely distracts from the much more immediate challenge of limiting warming to $2^{\circ} \mathrm{C}$.}

T he campaign to establish 350 parts per million (p.p.m.) as a long-term target carbon dioxide concentration has acquired considerable momentum despite relatively little support for this specific number in the scientific literature. As one of the highest-profile scientific endorsements of 350 p.p.m., the essay by Rockström et al. (Nature 461, 472-475; 2009) will no doubt be heavily cited in the run-up to the UN climate negotiations in Copenhagen this December. While the underlying argument for limiting anthropogenic warming to below $2{ }^{\circ} \mathrm{C}$ is indisputable, attempts to define a 'climate boundary' in terms of long-term $\mathrm{CO}_{2}$ concentrations represent an unnecessary distraction. The problem is not that 350 p.p.m. is too high or too low a threshold, but that it misses the point. The actions required over the next couple of decades to avoid dangerous climate change are the same regardless of the long-term concentration we decide to aim for.

Rockström et al. define planetary boundaries as "scientifically informed values of the control variable established by societies at a 'safe' distance from dangerous thresholds". The 350-p.p.m. boundary fails on at least two counts. First, the concentration of carbon dioxide at some unspecified date in the future is not a "control variable" in any recognizable sense.

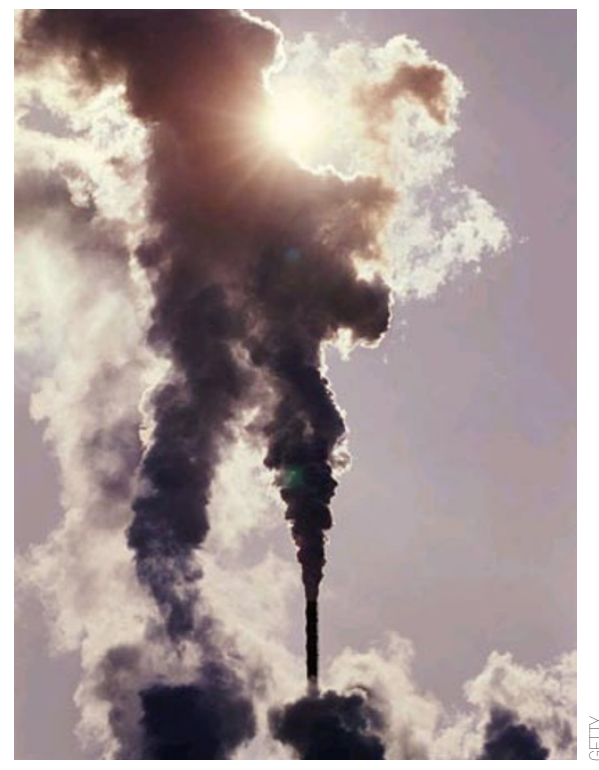

behaviour of the carbon cycle, which is highly uncertain. Even more, it will depend on how our descendants manage the carbon budget over the ensuing centuries, which is more uncertain still. Although emissions over the next few decades could commit us to much higher atmospheric $\mathrm{CO}_{2}$ concentrations in the long term, whether they are 350 p.p.m. or 450 p.p.m. in the year 3000 is not something anyone living in the twenty-first century could meaningfully claim to control.

Second, the scientific justification that carbon dioxide levels must equilibrate at 350 p.p.m. or lower to avoid more than $2{ }^{\circ} \mathrm{C}$ of warming appears to depend on a rather questionable estimate of the 'climate sensitivity' - the very long-term warming response to a doubling of atmospheric carbon dioxide. Rockström et al. acknowledge that the strength of feedbacks in the present-day climate suggests a most likely value for climate sensitivity of $3{ }^{\circ} \mathrm{C}$, with a 'likely' (one-standard-error) uncertainty range of $2-4.5^{\circ} \mathrm{C}$. Yet they cite evidence from paleoclimate research (Open Atmos. Sci. J. 2, 217-231; 2009) that, in the past, additional feedbacks due to polar ice-sheet melting and poleward shifts in vegetation resulted in a climate sensitivity of $6^{\circ} \mathrm{C}$, with a 'likely' range of $4-8^{\circ} \mathrm{C}$. They invoke this higher number, assuming 